\title{
Challenging diagnosis of congenital hyperinsulinism in two infants of diabetic mothers with rare pathogenic $K C N J 11$ and HNF4A gene variants
}

\author{
Lina Huerta-Saenz ${ }^{1,2,3,4,7}$, Carol Saunders ${ }^{3,5,6}$ and Yun $\operatorname{Yan}^{1,2,3^{*}}$ (D)
}

\begin{abstract}
Background: Congenital hyperinsulinism $(\mathrm{CHI})$ is the leading cause of persistent hypoglycemia in infants. The infants of diabetic mothers (IDMs) very frequently present with neonatal hypoglycemia associated to transient hyperinsulinism however the incidence of $\mathrm{CHI}$ in IDMs is unknown.

Case presentation: Here we report 2 cases of $\mathrm{CHI}$ where the diagnoses were challenged and delayed because both patients were infants of diabetic mothers (IDMs) and had concomitant complicated medical conditions. Case 1 was heterozygous for a likely pathogenic variant in KCNJ11(p.Arg206Cys), and Case 2 was heterozygous for a pathogenic HNF4A variant, (p.Arg267Cys). HNF4A-associated CHI is very rare, and this particular case had a clinical phenotype quite different from that of previously described HNF4A-CHI cases.

Conclusions: This case series is one of few reports in the medical literature describing two IDMs with persistent recurrent hypoglycemia secondary to $\mathrm{CHI}$, and a different clinical phenotype for HNF4A-associated CHI. IDMs typically present with transient hyperinsulinism lasting no more than 2-3 days. Since being an IDM does not exclude $\mathrm{CHI}$, this diagnosis should always be considered as the mostly likely etiology if neonatal hypoglycemia persists longer than the described time frame and genetic testing for $\mathrm{CHI}$ confirmation is highly suggested.
\end{abstract}

Keywords: Congenital Hyperinsulinism, Infant of diabetic mother, Neonatal hypoglycemia

\section{Background}

Congenital hyperinsulinism $(\mathrm{CHI})$ is the leading cause of persistent hypoglycemia in infants, causing neurodevelopmental and cognitive delays in up to $25-50 \%$ of affected children [1]. Early recognition and appropriate treatment are important to prevent such adverse outcomes.

The estimated incidence of $\mathrm{CHI}$ is reported to be as low as 1/50,000 live births in Holland to as high as $1 /$ 2500 in geographic areas where consanguinity is highly frequent, such as Saudi Arabia [2]. CHI is caused by genetic defects that cause disease through changes in channels expression/activity, transcription factors expression and disturbed enzyme activities. More frequently is

\footnotetext{
* Correspondence: yyan@cmh.edu

${ }^{1}$ Children's Mercy Kansas City, Division of Pediatric Endocrinology, 3101 Broadway Blvd, Kansas City, MO 64111, USA

${ }^{2}$ Children's Mercy- Wichita Specialty Clinic, Wichita, KS, USA

Full list of author information is available at the end of the article
}

increased activity rather than enzymes deficiency All these defects cause the common finding of recurrent episodes of hyperinsulinemic hypoglycemia due to an inappropriate secretion of insulin by the pancreatic beta-cells [3].

In 2016, there were 11 genes known to be associated with monogenic forms of $\mathrm{CHI}(A B C C 8, K C N J 11$, GLUD1, GCK, HADH1, UCP2, MCT1, HNF4A, HNF1A, $H K 1$, and PGM1) [4, 5]. Variants in the $A B C C 8$ and KCNJ11 genes together comprise approximately $90 \%$ of the identified cases of diazoxide-unresponsive $\mathrm{CHI}$ [6]. These genes encode SUR-1 and Kir6.2, respectively, which comprise two subunits of $\mathrm{K}_{\mathrm{ATP}}-\mathrm{HI}$, the beta-cell plasma dependent membrane ATP-potassium channel $[7,8]$. Most pathogenic variants in these 2 genes are recessive and cause loss of function; however, some cases of dominantly inherited inactivating mutations have been reported. In the past, clinical phenotype of patients

(c) The Author(s). 2018 Open Access This article is distributed under the terms of the Creative Commons Attribution 4.0 International License (http://creativecommons.org/licenses/by/4.0/), which permits unrestricted use, distribution, and reproduction in any medium, provided you give appropriate credit to the original author(s) and the source, provide a link to the Creative Commons license, and indicate if changes were made. The Creative Commons Public Domain Dedication waiver (http://creativecommons.org/publicdomain/zero/1.0/) applies to the data made available in this article, unless otherwise stated. 
with dominant variants was different from those with recessive variants but the biochemical phenotype was not different [9]. However, in 2013 Snider et al. published a large cohort of 417 children with $\mathrm{CHI}$ whose genotype-phenotype correlations were most successful if they have GLUD1, GCK, and recessive $\mathrm{K}_{\mathrm{ATP}}$ mutations [6]. Many of these correlations were challenging due to the high frequency of novel missense $\mathrm{K}_{\mathrm{ATP}}$ mutations because these defects might be either recessive or dominant and if dominant these could be either responsive or unresponsive to diazoxide. In these cases, mutation analysis including parental testing should be considered. However, the existence of novel $\mathrm{K}_{\mathrm{ATP}}$ missense mutations variability (recessive/dominant) in adult carriers is typically unknown because they are frequently asymptomatic unless challenged with fasting or protein tolerance test $[6,9,10]$.

Diazoxide, the first-line treatment for $\mathrm{CHI}$, acts by opening the $\mathrm{K}_{\mathrm{ATP}}$-channel and decreasing insulin secretion [11]. The effect of the gene variant on $\mathrm{K}_{\mathrm{ATP}}$-channel expression determines the clinical phenotype and the response to diazoxide [4]. Octreotide, a second-line agent, is a long-acting somatostatin analog that decreases insulin secretion through hyperpolarization of the beta-cells and inhibition of calcium channels but has been associated with treatment failure due to tachyphylaxis and fatal necrotizing enterocolitis [8].

There are two distinct histologic forms of CHI: focal and diffuse. In a published cohort of 52 infants with $\mathrm{CHI}$ treated from 1985 to 1998 , twenty-two had focal CHI and the rest had diffuse CHI. Only one neonate with focal $\mathrm{HI}$ and two with diffuse $\mathrm{HI}$ responded to treatment with diazoxide. All the other infants require pancreatic surgery to achieve cure [12].

Variants in a third gene, HNF4A, are associated with transient $\mathrm{CHI}$ in early infancy, despite also causing maturity-onset diabetes of the young (MODY 1) [13]. HNF4A variants are typically rare and the incidence varies per population but have been described as the third most common cause of diazoxide-responsive $\mathrm{CHI}$ in a large cohort of 300 patients with $\mathrm{CHI}$ from United Kingdom [14, 15].

The infants of diabetic mothers (IDM) born with macrosomia typically present frequent metabolic complications including hypoglycemia, jaundice, respiratory distress, asphyxia and are in greater need of intensive care as reported by Looreda-Garcia et al. in a large cohort of 18,005 newborns where $10 \%$ were infants of diabetic mothers [16]. The hyperinsulinemic hypoglycemia seen in IDMs occurs secondary to transient hyperinsulinism but it does not last longer than 2 or 3 days [7].

The current 2011 American Academy of Pediatrics guidelines for postnatal glucose homeostasis in healthy late-preterm and term infants mandate that persistent hypoglycemia, lower than $25 \mathrm{mg} / \mathrm{dL}$ from birth to $4 \mathrm{~h}$ of age, or lower than $35 \mathrm{mg} / \mathrm{dL}$ from 4 to $24 \mathrm{~h}$ of age after attempts to reefed, requires treatment with intravenous (IV) glucose [17]. These prior AAP guidelines focused on when to screen infants for hypoglycemia and when to provide treatment but did not address the etiology work up procedure for prolonged and recurrent neonatal hypoglycemia. The Pediatric Endocrine Society recommendations published in 2015 considered the interpretation and response to plasma glucose (PG) concentration during the first 2 days of life is controversial however the mean PG concentration in normal newborns increases with time and by $72 \mathrm{~h}$ of age is similar to those in older infants and children. Therefore, these guidelines suggest delaying diagnostic evaluations until 2-3 days after birth [17].

Here we report 2 cases of IDMs with rare genetic variants of $\mathrm{CHI}$ whose final diagnoses of $\mathrm{CHI}$ were complicated and delayed because the patients were IDMs and had concomitant challenging medical conditions.

\section{Cases presentation}

\section{Case 1}

A Hispanic male infant was born large for gestational age (LGA) (birth weight $4.11 \mathrm{~kg}$, above 100th percentile and length $51 \mathrm{~cm}, 98.6$ th percentile) at 34 weeks to a 17-year-old mother with uncontrolled gestational diabetes and pre-eclampsia. No family history iof hypoglycemia was reported. He was born by emergency $\mathrm{C}$-section at an outside medical center when fetal monitoring revealed a flat strip. At the time of delivery, his APGAR scores were 2 at $1 \mathrm{~min}$, and 6 at $5 \mathrm{~min}$. His initial arterial blood gas was $\mathrm{pH} 7.13, \mathrm{pO} 265, \mathrm{pCO} 2$ $40 \mathrm{mmHg}$, base excess (-9.2). His initial plasma glucose level was $7 \mathrm{mg} / \mathrm{dL}$. He received an IV bolus with D12.5\%, followed by IV fluids (IVF) with a glucose infusion rate (GIR) of $6.9 \mathrm{mg} / \mathrm{kg} / \mathrm{min}$. The infant was transferred to our hospital at day of life (DOL) 2 for respiratory distress syndrome (RDS), supraventricular tachycardia, and hypoplastic aortic arch as well as persistent hypoglycemia.

During his hospital stay, the GIR was gradually increased to $16 \mathrm{mg} / \mathrm{kg} / \mathrm{min}$. Polycose supplement was added to his feeds with the goal of maintaining plasma glucose levels close to $70 \mathrm{mg} / \mathrm{dL}$ when titrating IV dextrose. However, on DOL 21, he developed hypoglycemic episodes (BG below $50 \mathrm{mg} / \mathrm{dL}$ ) after IV dextrose was weaned off and despite consuming $26 \mathrm{cal} / \mathrm{oz}$. of formula. Extensive workup for CHI was initiated on DOL 25, and the results revealed an elevated insulin level of 16.3 $\mathrm{mcIU} / \mathrm{mL}$ coincident with a plasma glucose level of $48 \mathrm{mg} / \mathrm{dL}$ and beta hydroxybutyrate level of less than $100 \mathrm{mcmol} / \mathrm{L}$. Ammonia, pyruvic acid, cortisol level, serum amino acids, acyl carnitine profile, and urine organic acids were all in the normal range (Table 1). A 
pediatric endocrinology consultation was performed and DNA sequencing for $\mathrm{CHI}$ was ordered, revealing a heterozygous maternally-inherited likely pathogenic variant in KCNJ11, c.616C > T (p.Arg206Cys). This variant has been previously reported in a family where it segregated with several affected individuals with CHI. It is rare in population databases (ExAC and gnomAD; 3/242,646 alleles) [18] and predicted by in silico tools (GERP, SIFT, PolyPhen) to be damaging [19]. Diazoxide was started and plasma glucose levels stabilized above $70 \mathrm{mg} / \mathrm{dL}$ at the dose of $15 \mathrm{mg} / \mathrm{kg} /$ day on DOL 30 . The patient was discharged home at DOL 71 with diazoxide at $10 \mathrm{mg} /$ $\mathrm{kg} /$ day. His plasma glucose was stable on a similar dose at the time of his last visit when he was 11 months old.

\section{Case 2}

A male infant was born small for gestational age (SGA) [birth weight $1.45 \mathrm{~kg}$ (4.7th percentile), and birth length, $40 \mathrm{~cm}$ (3.5th percentile)] at 33 weeks of gestational age to a 35-year-old mother with gestational diabetes and pregnancy-induced hypertension (PIH) at a local medical center. His mother managed her gestational diabetes with diet control only. Family history was remarkable for type 2 diabetes in the maternal grandmother. No family history of hypoglycemia reported. Paternal history was unknown. His APGAR scores were 1, 6, and 10 at 1, 5, and $10 \mathrm{~min}$, respectively. He developed persistent hypoglycemia on DOL 5 (Plasma Glucose $=43 \mathrm{mg} / \mathrm{dL}$ ) and also had transient RDS.

Treatment for hypoglycemia was started with dextrose $10 \%$ IVF with GIR at $6-10 \mathrm{mg} / \mathrm{kg} /$ day in addition to increased oral feeds. He also received hydrocortisone treatment $\left(30 \mathrm{mg} / \mathrm{m}^{2} /\right.$ day $)$ secondary to low cortisol

Table 1 Critical Sample Laboratory Data of Case 1 (KCNJ11 gene mutation)

\begin{tabular}{lll}
\hline Parameter (DOL \#26: 2/26/2013) & Laboratory Value & Normal Range \\
\hline POC Blood glucose & $48 \mathrm{mg} / \mathrm{dL}$ & $70-99 \mathrm{mg} / \mathrm{dL}$ \\
Serum Blood Glucose & $58 \mathrm{mg} / \mathrm{dL}$ & $70-99 \mathrm{mg} / \mathrm{dL}$ \\
Serum Cortisol & $23 \mathrm{mcg} / \mathrm{dL}$ & $7-25 \mathrm{mcg} / \mathrm{dL}$ \\
Serum Growth Hormone & $4.6 \mathrm{ng} / \mathrm{mL}$ & $0-7 \mathrm{ng} / \mathrm{mL}$ \\
Serum Insulin & $16.3 \mathrm{mclU} / \mathrm{mL}$ & $2-18 \mathrm{mclU} / \mathrm{mL}$ \\
Beta Hydroxybutyrate & Less than 100 & $0-269 \mathrm{mcmol} / \mathrm{L}$ \\
Urinary Ketones & N/A & N/A \\
Serum Lactic Acid & $1 \mathrm{mmol} / \mathrm{L}$ & $0.7-2.1 \mathrm{mmol} / \mathrm{L}$ \\
Serum Pyruvic Acid & $0.08 \mathrm{mmol} / \mathrm{L}$ & $0.08-0.16 \mathrm{mmol} / \mathrm{L}$ \\
Free Fatty Acids $^{\text {Plasma Acyl carnitine profile }}{ }^{a}$ & Not collected & N/A \\
Urine Organic Acids $^{a}$ & Normal & \\
Serum Ammonia $^{a}$ & $10 \mathrm{mcmol} / \mathrm{L}$ & $10-62 \mathrm{mcmol} / \mathrm{L}$ \\
Serum Amino Acid Profile $^{a}$ & Normal & N/A \\
\hline
\end{tabular}

(a) Samples were collected on DOL\#46 (03/05/2013) level during a prior hypoglycemic event $(4.3 \mathrm{mcg} / \mathrm{dL})$ from DOL 12 to DOL 20. Hypoglycemia recurred after discontinuing hydrocortisone therapy as well as dextrose containing IVF, and then our pediatric endocrinology team was consulted. Critical labs were obtained on DOL 21 (Table 2). Urine ketones were negative but the beta hydroxybutyrate was not obtained at outside hospital. The physical exam of this infant was negative for concerning findings for hypopituitarism.

High-dose ACTH stimulation testing (abbreviated) was performed due to random low cortisol level and the infant responded adequately with a stimulated cortisol level at $29.7 \mathrm{mcg} / \mathrm{dL}$ and baseline cortisol level at $10.4 \mathrm{mcg} / \mathrm{dL}$. Serum ammonia and lactic acid levels were normal. A glucagon challenge test was recommended by the pediatric endocrine team but was not performed. The infant was started on diazoxide at $15 \mathrm{mg} / \mathrm{kg} /$ day with good response. DNA sequencing for $\mathrm{CHI}$ revealed a heterozygous pathogenic missense variant in exon 7 of HNF4A, p.Arg267Cys; c.799C > T; legacy Arg245Cys). This variant affects a highly conserved amino acid and is predicted to be deleterious by in silico tools. It has been previously detected in patients with MODY 1 [20], and different substitutions affecting this same codon (p.Arg267Ser and p.Arg267Gly) have been reported [21]. This variant is absent from population databases including GnomAD, ExAC and Leiden Open Variation Database. Parental testing was not performed due to maternal refusal and unavailability of father. Renal ultrasound, liver function tests, and urinalysis of this patient were normal. The patient responded well to diazoxide, which was gradually tapered based on POC home glucose values in the range of $70-100 \mathrm{mg} / \mathrm{dL}$ and hemoglobin $\mathrm{A} 1 \mathrm{C}$, and eventually discontinued at 6 months of age. Fasting challenge test was not performed before total discontinuation of diazoxide. Infant remained euglycemic at the time of his last visit in clinic (2 years 9 months of age).

\section{Discussion}

In these 2 cases, the diagnostic workup for $\mathrm{CHI}$ was complicated by their status as infants of diabetic mothers. For both, the standard treatment for neonatal hypoglycemia was provided but the specific work up for $\mathrm{CHI}$ was not performed until both infants were older than 3 weeks of life. Case 1 had perinatal asphyxia, prematurity, and sepsis as his underlying diagnoses and therefore his hypoglycemia was initially considered to be secondary to these underlying diagnoses rather than due to $\mathrm{CHI}$, and Case 2 was presumed to have transient hyperinsulinism due to his small for gestational age condition, in addition to being an IDM with concomitant PHI.

The incidence of $\mathrm{CHI}$ in IDMs is not well known considering the absence of published reports in the 
Table 2 Critical Sample Laboratory Data of Case 2 (HNF4A gene mutation)

\begin{tabular}{lll}
\hline Parameter & Laboratory Value & Normal Range \\
\hline POC Blood glucose & $43 \mathrm{mg} / \mathrm{dL}$ & $70-99 \mathrm{mg} / \mathrm{dL}$ \\
Serum Blood Glucose & $46 \mathrm{mg} / \mathrm{dL}$ & $70-99 \mathrm{mg} / \mathrm{dL}$ \\
Serum Cortisol & $8.3 \mathrm{mcg} / \mathrm{dL}$ & $7-25 \mathrm{mcg} / \mathrm{dL}$ \\
Serum Growth Hormone & $11.3 \mathrm{ng} / \mathrm{mL}$ & $0-7 \mathrm{ng} / \mathrm{mL}$ \\
Serum Insulin & $1.5 \mathrm{mclU} / \mathrm{mL}$ & $3-25 \mathrm{mclU} / \mathrm{mL}$ \\
Beta Hydroxybutyrate & $\mathrm{N} / \mathrm{A}$ & $\mathrm{N} / \mathrm{A}$ \\
Lactic Acid & $1.6 \mathrm{mmol} / \mathrm{L}$ & $0.5-2.2 \mathrm{mmol} / \mathrm{L}$ \\
Ammonia & $38 \mathrm{mcmol} / \mathrm{L}$ & $11-32 \mathrm{mcmol} / \mathrm{L}$ \\
\hline
\end{tabular}

literature. However, considering IDMs have higher rates of prolonged hospitalization at the NICU services is remarkably important to bring these findings to the attention of pediatricians and neonatologists to increase awareness about the need of considering $\mathrm{CHI}$ as the main etiology of prolonged and recurrent hypoglycemia in all neonates including the infants of diabetic mothers.

The most common risks for neonates developing abnormal postnatal glucose homeostasis include being SGA, LGA, IDMs, history of perinatal asphyxia and prematurity [17]. Case 1 was born LGA, IDM, premature and had asphyxia at birth, leading perinatal stress-induced hyperinsulinism (HI) to be included on his differential diagnosis. Stress-induced HI can be seen in asphyxia, as well as maternal toxemia and intrauterine growth retardation [22]. This former medical condition can persist for several weeks after birth, but it usually remits spontaneously. Perinatal asphyxia in Case 1 was probably one of the confounding factors contributing to the delay in considering $\mathrm{CHI}$ as the most likely etiology of his prolonged and recurrent hypoglycemia. Case 2 was also an IDM, premature but born SGA and these three risk factors played an important role in the delay of considering $\mathrm{CHI}$ as the final etiology of his persistent neonatal hypoglycemia.

Pertinent workup for the etiology of persistent neonatal hypoglycemia includes obtaining critical samples in a timely manner and performing genetic testing. Critical samples for evaluation of hypoglycemia include plasma glucose, beta-hydroxybutyrate, carbon dioxide, lactate, free fatty acids, cortisol, growth hormone, total/free carnitine, acyl carnitine profile, C-peptide, and pro-insulin levels. In 2015, the Pediatric Endocrine Society (PES) of the United States published new recommendations for evaluation and management of persistent hypoglycemia in neonates, infants, and children and the specific timeframes to start performing work up for $\mathrm{CHI}$ were also described [23]. Adherence to the current PES recommendations in all NICUs and nurseries would potentially avoid delays on neonatal hypoglycemia etiology work up and this potentially would lead to a prompt diagnosis of CHI. Prior AAP guidelines published in 2011 failed to address the diagnosis and management of disorders causing recurrent and prolonged hypoglycemia beyond the neonatal period [17].

DNA sequencing is remarkably important when $\mathrm{CHI}$ is suspected because it contributes to accurate medical treatment, genetic counseling, potential distinction between focal and diffuse disease, determination of the likelihood of good response to medications, and consideration of early pancreatic surgery. In a cohort study from the United Kingdom of infants who underwent rapid sequencing, 27 patients $(26 \%)$ were positive for $A B C C 8$ variants and 5 of them $(5 \%)$ were positive for $K C N J 11$ variants [24]. Of the 5 with KCNJ11-variants, 2 underwent subtotal pancreatectomy. A significant proportion (18\%) who tested positive for $A B C C 8$ or $K C N J 11$ variants achieved euglycemia with medical treatment. All infants with maternal heterozygous mutations achieved remission, leading to the conclusion that maternally inherited variants may confer a higher rate of remission.

Genetic testing is also very helpful in CHI because even though patients with inactivating mutations of GCK (MODY 2), inactivating mutations of hepatocyte nuclear factorHNF1A (MODY 3) and HNF4A (MODY 1) can present as congenital $H I$ in neonates they can later evolve in early adulthood into insulinopenic diabetes; and activating mutations of the KATP channel subunits can cause either severe permanent neonatal diabetes or a mild increased susceptibility to adult-onset diabetes [5].Case 1 was heterozygous for a maternally inherited likely pathogenic variant in KCNJ11. This variant has been reported in one family where it segregated with disease in four symptomatic hypoglycemic individuals [19]. It is rare (present in only 2 of $\sim 12,000$ alleles) in the general population and predicted by in silico tools to be damaging. However, this is the first time this variant has been reported in an IDM.

The phenotype of Case 2 (SGA) did not follow the classical phenotype of IDMs who are typically born with macrosomia. Most infants reported with $H N F 4 A$ variants had increased birth weight and macrosomia [25], and they also had transient $\mathrm{CHI}$ requiring diazoxide therapy between 3 months and 8 years [26]. Case 2 was born SGA in contrast to the prior reports of HNF4A-associated CHI infants (E.g. p.R63W mutation) who are typically born with macrosomia [26]. However, one recent report of an infant with HNF4A-CHI and carrier of the p.R63W mutation described that infant was born with normal weight but this infant was not an IDM [27]. It is not clear if the SGA phenotype of Case 2 was secondary to his underlying HNF4A variant, his prematurity (considering that insulin is an important growth factor in the third trimester of pregnancy) or if this was a 
consequence of the intrauterine growth retardation associated with his maternal PIH.

With regard to his response to medical treatment, diazoxide therapy in Case 2 was rapidly tapered and successfully discontinued similar to the prior HNF4A case reported by Flanagan in 2010 [14].

It is important to describe this transient hyperinsulinism clinical course on Case 2 because his successful response to diazoxide could be associated to his R267C gene variant, and could be also linked to future progression to MODY. Even though we recommended genetic testing for both parents, and mother was referred to genetics for testing and counseling (father was not available and his family medical history was unknown) she was not able to pursue genetic testing due to unavailable medical insurance coverage. We discussed with mother the potential implications of genetic testing for her diagnosis (she has high risk to be a HNF4A carrier) but she reported to be healthy and refused further evaluation with OBGYN.

\section{Conclusions}

This case series is one of the few reports describing two IDMs with persistent recurrent hypoglycemia secondary to genetic $\mathrm{CHI}$, and an atypical clinical phenotype for $H N F 4 A$-associated CHI. Prompt consideration of $\mathrm{CHI}$ as the most likely etiology of recurrent and prolonged neonatal hypoglycemia even in IDMs is important to facilitate prompt consultation with endocrinology, and appropriate timely workup including genetic testing as recommended by the current PES clinical guidelines [23]. Transient neonatal hypoglycemia in an IDM is not expected to last more than 2-3 days. In all the cases of neonatal hypoglycemia persisting beyond this timeframe, including infants of diabetic mothers, $\mathrm{CHI}$ should be considered as the presumed etiology.

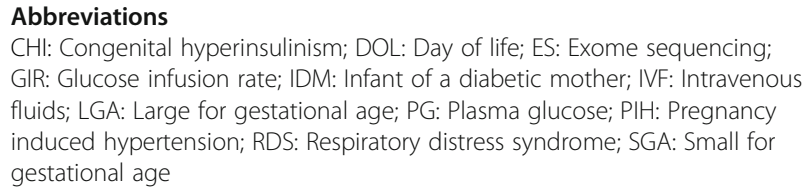
GIR: Glucose infusion rate; IDM: Infant of a diabetic mother; IVF: Intravenous fluids; LGA: Large for gestational age; PG: Plasma glucose; PIH: Pregnancy induced hypertension; RDS: Respiratory distress syndrome; SGA: Small for gestational age

\section{Acknowledgments}

Thank you to the Children's Mercy Hospital - Medical writing center for the detailed review of this manuscript.

\section{Availability of data and materials}

All the clinical, demographic, laboratory results and genetic testing results are available in the electronic medical records of our institution.

\section{Authors' contributions}

LHS created these case series manuscript after evaluating, performing diagnosis and treating these 2 cases. CS performed the exome sequencing testing of these 2 infants and analyzed both ES reports. YY evaluated and treated case 1 with LHS, and mentored LHS in the creation and writing of this manuscript. All the final manuscript versions were reviewed by LHS, YY and CS. All authors read and approved the final manuscript.

\section{Ethics approval and consent to participate}

The IRB at Children's Mercy Hospital does not require IRB submission for publications of case reports or series describing less than 3 patients or study subjects but obtaining an informed consent from study subjects or their legal representatives is recommended for publication purposes.

\section{Consent for publication}

Case 1 was lost to follow up in clinic and consent was not obtained, but Case 2 consent was obtained before the submission of this manuscript and a copy is available for review by the Editor-on-Chief of this journal at any time.

\section{Competing interests}

The authors declare that they have no competing interests.

\section{Publisher's Note}

Springer Nature remains neutral with regard to jurisdictional claims in published maps and institutional affiliations.

\section{Author details}

${ }^{1}$ Children's Mercy Kansas City, Division of Pediatric Endocrinology, 3101 Broadway Blvd, Kansas City, MO 64111, USA. ${ }^{2}$ Children's Mercy- Wichita Specialty Clinic, Wichita, KS, USA. ${ }^{3}$ University of Missouri-Kansas City, Kansas City, MO, USA. ${ }^{4}$ University of Kansas Medical Center-Wichita School of Medicine, Wichita, KS, USA. ${ }^{5}$ Center for Pediatric Genomic Medicine Children's Mercy Hospital, Kansas City, MO, USA. ${ }^{6}$ Department of Pathology and Laboratory Medicine, Children's Mercy Hospital, Kansas City, MO, USA.

${ }^{7}$ Present address: Penn State College of Medicine, Penn State Children's

Hospital- Division of Pediatric Endocrinology and Diabetes, Hershey, PA, USA.

Received: 19 April 2018 Accepted: 9 July 2018

Published online: 17 July 2018

\section{References}

1. Steinkrauss $L$, et al. Effects of hypoglycemia on developmental outcome in children with congenital hyperinsulinism. J Pediatr Nurs. 2005;20(2):109-18.

2. Mathew PM, et al. Persistent neonatal hyperinsulinism. Clin Pediatr (Phila). 1988;27(3):148-51.

3. Arnoux JB, et al. Congenital hyperinsulinism: current trends in diagnosis and therapy. Orphanet J Rare Dis. 2011;6:63.

4. Stanley CA, De Leon DD. Monogenic Hyperinsulinemic Hypoglycemia Disorders. Basel: Karger; 2012.

5. Stanley CA. Perspective on the genetics and diagnosis of congenital hyperinsulinism disorders. J Clin Endocrinol Metab. 2016;10(3):815-26.

6. Snider KE, et al. Genotype and phenotype correlations in 417 children with congenital hyperinsulinism. J Clin Endocrinol Metab. 2013;98(2):E355-63.

7. Stanley CA. Advances in diagnosis and treatment of hyperinsulinism in infants and children. J Clin Endocrinol Metab. 2002:87(11):4857-9.

8. Lord K, De Leon DD. Monogenic hyperinsulinemic hypoglycemia: current insights into the pathogenesis and management. Int J Pediatr Endocrinol. 2013;2013(1):3.

9. Pinney SE, et al. Clinical characteristics and biochemical mechanisms of congenital hyperinsulinism associated with dominant KATP channel mutations. J Clin Invest. 2008;118(8):2877-86.

10. Macmullen CM, et al. Diazoxide-unresponsive congenital hyperinsulinism in children with dominant mutations of the beta-cell sulfonylurea receptor SUR1. Diabetes. 2011;60(6):1797-804.

11. De Leon DD, Stanley CA. Mechanisms of disease: advances in diagnosis and treatment of hyperinsulinism in neonates. Nat Clin Pract Endocrinol Metab. 2007;3(1):57-68

12. de Lonlay-Debeney $P$, et al. Clinical features of 52 neonates with hyperinsulinism. N Engl J Med. 1999;340(15):1169-75.

13. Stanescu DE, et al. Novel presentations of congenital hyperinsulinism due to mutations in the MODY genes: HNF1A and HNF4A. J Clin Endocrinol Metab. 2012;97(10):E2026-30.

14. Flanagan SE, et al. Diazoxide-responsive hyperinsulinemic hypoglycemia caused by HNF4A gene mutations. Eur J Endocrinol. 2010;162(5):987-92.

15. Kapoor RR, et al. Clinical and molecular characterisation of 300 patients with congenital hyperinsulinism. Eur J Endocrinol. 2013;168(4):557-64.

16. Lloreda-García JM, et al. Perinatal outcome of macrosomic infants born to diabetic versus non-diabetic mothers. Endocrinol Nutr. 2016;63(8):409-13. 
17. Committee on, F., Newborn, and D.H. Adamkin. Postnatal glucose homeostasis in late-preterm and term infants. Pediatrics. 2011;127(3):575-9.

18. Lek $\mathrm{M}$, et al. Analysis of protein-coding genetic variation in 60,706 humans. Nature. 2016;536(7616):285-91.

19. Bennett JT, et al. Molecular genetic testing of patients with monogenic diabetes and hyperinsulinism. Mol Genet Metab. 2015;114(3):451-8.

20. Colclough $\mathrm{K}$, et al. Mutations in the genes encoding the transcription factors hepatocyte nuclear factor 1 alpha and 4 alpha in maturity-onset diabetes of the young and hyperinsulinemic hypoglycemia. Hum Mutat. 2013;34(5):669-85.

21. LOVD. Monogenic Diabetes-Hepatocyte Nuclear Factor 4 alpha (HNF4A). Available from: https://grenada.lumc.nl/LOVD2/diabetes/home.php?select_ $\mathrm{db}=$ HNF4A.

22. Collins JE, Leonard JV. Hyperinsulinism in asphyxiated and small-for-dates infants with hypoglycaemia. Lancet. 1984;2(8398):311-3.

23. Thornton PS, et al. Recommendations from the pediatric Endocrine Society for evaluation and Management of Persistent Hypoglycemia in neonates, infants, and children. J Pediatr. 2015;167(2):238-45.

24. Banerjee I, et al. The contribution of rapid KATP channel gene mutation analysis to the clinical management of children with congenital hyperinsulinism. Eur J Endocrinol. 2011;164(5):733-40.

25. Pearson ER, et al. Macrosomia and hyperinsulinaemic hypoglycaemia in patients with heterozygous mutations in the HNF4A gene. PLoS Med. 2007; 4(4):e118.

26. Kapoor RR, et al. Persistent hyperinsulinemic hypoglycemia and maturityonset diabetes of the young due to heterozygous HNF4A mutations. Diabetes. 2008:57(6):1659-63.

27. Improda N, et al. Hepatocyte nuclear Factor-4 alfa mutation associated with Hyperinsulinaemic Hypoglycaemia and atypical renal Fanconi syndrome: expanding the clinical phenotype. Horm Res Paediatr. 2016;86(5):337-41.

Ready to submit your research? Choose BMC and benefit from:

- fast, convenient online submission

- thorough peer review by experienced researchers in your field

- rapid publication on acceptance

- support for research data, including large and complex data types

- gold Open Access which fosters wider collaboration and increased citations

- maximum visibility for your research: over $100 \mathrm{M}$ website views per year 